\title{
Inter-comparison of four different carbon monoxide measurement techniques and evaluation of the long-term carbon monoxide time series of Jungfraujoch
}

\author{
C. Zellweger, C. Hüglin, J. Klausen, M. Steinbacher, M. Vollmer, and B. Buchmann \\ Empa, Swiss Federal Laboratories for Materials Testing and Research, Laboratory for Air Pollution/Environmental \\ Technology, 8600 Dübendorf, Switzerland
}

Received: 19 November 2008 - Published in Atmos. Chem. Phys. Discuss.: 26 January 2009

Revised: 18 May 2009 - Accepted: 18 May 2008 - Published: 2 June 2009

\begin{abstract}
Despite the importance of carbon monoxide (CO) for the overall oxidative capacity of the atmosphere, there is still considerable uncertainty in ambient measurements of CO. To address this issue, an inter-comparison between four different measurement techniques was made over a period of two months at the high-alpine site Jungfraujoch (JFJ), Switzerland. The measurement techniques were Nondispersive Infrared Absorption (NDIR), Vacuum UV Resonance Fluorescence (VURF), gas chromatographic separation with a mercuric oxide reduction detector $(\mathrm{GC} / \mathrm{HgO})$, and gas chromatographic separation followed by reduction on a nickel catalyst and analysis by a flame ionization detector (GC/FID). The agreement among all techniques was better than $2 \%$ for one-hourly averages, which confirmed the suitability of the NDIR method for CO measurements even at remote sites. The inter-comparison added to the validation of the 12-year record (1996-2007) of continuous CO measurements at JFJ. To date this is one of the longest time series of continuous $\mathrm{CO}$ measurements in the free troposphere over Central Europe. This data record was further investigated with a focus on trend analysis. A significant negative trend was observed at JFJ showing a decrease of $21.4 \pm 0.3 \%$ over the investigated period, or an average annual decrease of $1.78 \% / \mathrm{yr}(2.65 \pm 0.04 \mathrm{ppb} / \mathrm{yr})$. These results were compared with emission inventory data reported to the Longrange Transboundary Air Pollution (LRTAP) Convention. It could be shown that long range transport significantly influences the CO levels observed at JFJ, with air masses of non-European origin contributing at least one third of the observed mole fractions.
\end{abstract}

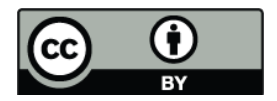

Correspondence to: C. Zellweger (christoph.zellweger@empa.ch)

\section{Introduction}

Carbon monoxide (CO) plays an important role in atmospheric chemistry. Reactions involving CO provide the dominant sink for the hydroxyl radical (Logan et al., 1981), and together with nitrogen oxides, the level of CO largely controls the overall oxidative capacity of the atmosphere. As a consequence, changes in $\mathrm{CO}$ emissions have an influence on climate by affecting methane and other greenhouse gases that are oxidized by the $\mathrm{OH}$ radical (Daniel and Solomon, 1998; Wild and Prather, 2000). Furthermore, CO plays an important role as a precursor of tropospheric ozone (Levy et al., 1997). CO has a relatively long atmospheric lifetime, ranging from 10 days in summer over continental regions to more than a year over polar regions in winter (Holloway et al., 2000b). This lifetime is long enough to make use of CO as a sound tracer for anthropogenic pollution.

In-situ measurements at remote sites are often made using gas chromatographic technique combined with a mercuric oxide detector $(\mathrm{HgO})$ (Novelli, 1999). This technique has a low detection limit and good precision; however, nonlinearity issues require careful calibration, and drift of standards with ambient $\mathrm{CO}$ mole fractions required for the calibration of this technique may further affect the accuracy of such measurements (Novelli et al., 2003). In addition to this method, several other techniques for the detection of $\mathrm{CO}$ with different temporal resolutions and detection limits have become available. The most common techniques currently applied comprise gas chromatographic (GC) techniques in combination with a flame ionization (FID) detector, and photometric methods such as non-dispersive infrared absorption (NDIR), vacuum ultra-violet resonance fluorescence (VURF) and tunable diode lasers spectroscopy (TDLS).

Despite its importance and the relatively large numbers of different measurement techniques employed, there is still considerable uncertainty in ambient measurements of $\mathrm{CO}$.

Published by Copernicus Publications on behalf of the European Geosciences Union. 
To date, no comprehensive $\mathrm{CO}$ instrument inter-comparisons have been published, although a few older studies compare TDLS instruments with $\mathrm{GC} / \mathrm{HgO}$ (Hoell et al., 1987), NDIR (Fried et al., 1991), and a VURF instrument (Holloway et al., 2000a). A short inter-comparison campaign with an NDIR and a VURF instrument at Jungfraujoch (JFJ) showed good correlation between the two techniques, but with absolute differences of 20-30 ppb (Whalley et al., 2004). These differences were attributed to the use of different calibration gases or interfering species in one of the techniques. A short inter-comparison between a $\mathrm{GC} / \mathrm{HgO}$ and an NDIR instrument showed good overall agreement (coefficient of determination $r^{2}=0.88$ ), but slightly larger deviations at mole fractions below $100 \mathrm{ppb}$ (Tsutsumi and Matsueda, 2000). A more recent study (Tanimoto et al., 2007) investigated differences between an NDIR and a $\mathrm{GC} / \mathrm{HgO}$ instrument, along with the use of different NDIR monitors. The agreement between the NDIR and the $\mathrm{GC} / \mathrm{HgO}$ instrument was within $10 \mathrm{ppb}$ for $60 \%$ of the one-hourly averages, but much larger deviations were found in the comparison of different NDIR monitors.

$\mathrm{CO}$ trends in the troposphere are important for the oxidizing capacity of the atmosphere and have been studied using data from observation networks. Early measurements of total column carbon monoxide from JFJ (Zander et al., 1989) showed an increase in CO of 1-2 ppb/yr between 1950 and 1980. A decrease of total column CO was reported for the 1980s and 1990s (annual change for selected periods of $-0.63 \%$ and $-0.27 \%$, respectively), and more stable mixing ratios were observed between 2004 and 2005 (Zander et al., 2008). A positive global trend was reported between 1980 and 1988 (Khalil and Rasmussen, 1988), but a negative trend was observed after 1988 (Khalil and Rasmussen, 1994). Decreasing CO mole fractions have also been reported between 1991 and 1993 (Novelli et al., 1994), and a more recent analysis showed an ongoing significant but less pronounced negative trend for global $\mathrm{CO}$ flask observations after 1995 (Novelli et al., 2003; Meszaros et al., 2005). Chevalier et al. (2008) analyzed long-term trends of CO over Western Europe. They estimated a negative trend of $-0.84 \pm 0.95$ ppb/yr for the Zugspitze (ZUG) site between 1991 and 2004. Most of the overall negative trend was attributed to the trend in spring (January-April; $-1.49 \pm 1.50 \mathrm{ppb} / \mathrm{yr}$ ), whereas no trend was evident for July-September $(-0.28 \pm 1.36 \mathrm{ppb} / \mathrm{yr})$.

$\mathrm{CO}$ measurements from JFJ have been used for the assessment of meteorological influences on trace gas levels (Forrer et al., 2000), and the validation of chemical transport models (Holloway et al., 2000b) and Lagrangian models (Folini et al., 2008). Independent emission control is becoming increasingly important for verification of international treaties such as the Montreal and Kyoto protocols. CO measurements are often used as a proxy for such estimations because $\mathrm{CO}$ emission inventories are relatively well known. For example, CO inventories from the European Monitoring and Evaluation Programme (EMEP) (Vestreng et al., 2005) in combination with in-situ $\mathrm{CO}$ and halocarbon measurements from
JFJ have successfully been used to estimate halocarbon emissions in Europe (Reimann et al., 2005). Especially applications combining data of emission inventories with in-situ $\mathrm{CO}$ measurements for source apportionment require $\mathrm{CO}$ data of known high quality.

This study presents results from an inter-comparison of several currently used in-situ techniques (NDIR, VURF, $\mathrm{GC} / \mathrm{HgO}, \mathrm{GC} / \mathrm{FID}$ ) for the measurement of atmospheric $\mathrm{CO}$, which are normally used in international programs and networks (such as GAW, EEA, EMEP). The measurements were carried out at the high alpine research station Jungfraujoch (JFJ), Switzerland. The aim of the study was to evaluate differences between various techniques and to estimate their uncertainties with respect to different temporal resolutions. In addition, the study added to the validation of an ongoing long NDIR CO time series of the JFJ site because it could be demonstrated that accurate and sufficiently precise $\mathrm{CO}$ measurements are possible with the NDIR technique for the use of source apportionment and trend analysis. The 12-year CO data record of JFJ is further presented with a focus on climatology and trends of $\mathrm{CO}$ in the remote continental troposphere.

\section{Experimental}

\subsection{Measurement site}

The high alpine research station Jungfraujoch (JFJ) $\left(46^{\circ} 33^{\prime} \mathrm{N}, 7^{\circ} 59^{\prime} \mathrm{E}, 3580 \mathrm{~m}\right.$ a.s.l.) is located on the main crest of the Bernese Alps, Switzerland. Details of the location and the measurements program can be found in the GAW Station Information System (GAWSIS, 2008). Further details of the station including the inlet system have been described elsewhere (Zellweger et al., 2000, 2003). JFJ is an excellent platform for long-term observations of the free troposphere due to its high elevation and year-round accessibility. It is part of the Swiss National Monitoring Network (NABEL) and one of the global stations of the Global Atmosphere Watch (GAW) programme.

\subsection{Instruments and calibration procedures}

\subsubsection{NDIR: Horiba APMA-360CE}

CO has been continuously monitored since 1996 using a commercially available NDIR monitor (APMA-360, Horiba) as part of the Swiss National Air Pollution Monitoring Network (NABEL). Modification of the instrument included drying of the air by a Nafion dryer in split flow mode (Permapure PD-50T-24"). The instrument was calibrated approximately in monthly intervals using a commercial CO calibration gas referenced against NIST (National Institute of Standards and Technology) SRM (Standard Reference Material) standards. Automatic instrument zero checks were performed every $49 \mathrm{~h}$ using zero air (heated $\mathrm{CO} / \mathrm{CO}_{2}$ converter, 
Molecular Sieve $3 \AA$, Sofnocat 423). The detection limit for individual 1-min samples is $20 \mathrm{pb}$, and the overall measurement uncertainty is estimated to be $\pm 5 \%(1 \sigma)$ (Zellweger et al., 2000), which includes the uncertainty of the calibration standard, the $\mathrm{H}_{2} \mathrm{O}$ interference, and the instrument precision.

In contrast to other commercially available NDIR CO monitors the Horiba APMA-360 uses "cross-flow modulation" to compensate for matrix effects in the NDIR absorption measurements. The air passes over a heated oxidation catalyst to selectively remove $\mathrm{CO}$ from the sample air with a frequency of $1 \mathrm{~Hz}$. Other commercial instruments use a gas filter correlation technique; these instruments have shown reduced performance concerning zero drift in the past. Results of this study can therefore not easily be transferred to gas filter correlation NDIR CO monitors. This limitation is also confirmed by a recent inter-comparison by Tanimoto et al. (2007). They compared a Horiba APMA-360 instrument with two gas filter correlation monitors and found significant deviations, which were attributed to both the analytical performance of the NDIR instruments and the reference gases.

\subsubsection{VURF: VUV-fluorescence: Aerolaser AL5001}

VUV fluorescence measurements were made using a commercially available instrument (Aerolaser AL5001). The instrument was calibrated every $60 \mathrm{~min}$ using a natural air (i.e. partly spiked/purified ambient air) working standard. The instrument was operated using $\mathrm{CO}_{2}$ (99.995\%) in $\mathrm{Ar}$ (99.9999\%) and $\mathrm{N}_{2}$ (99.9999\%) with an additional purifier (Aeronex Gate Keeper SS-400KGC-I-4S) as auxiliary gases. The sensitivity of the instrument decreased from initially 40 counts per second (cps) per ppb to $10 \mathrm{cps}$ per ppb at the end of the campaign, which is still above the specified limits for operation. The operating principle is described elsewhere (Gerbig et al., 1999).

\subsubsection{GC/FID: Agilent 6890N GC}

An Agilent 6890-N gas chromatograph equipped with a flame ionization detector (FID) was used for the detection of $\mathrm{CO}$ and $\mathrm{CH}_{4}$. $\mathrm{CO}$ was analyzed as $\mathrm{CH}_{4}$ after passing a hydrogen-flushed nickel catalyst heated to $375^{\circ} \mathrm{C}$. Chromatographic separation was achieved isothermally at $60^{\circ} \mathrm{C}$ by means of a Unibeads $1 \mathrm{~S}$ and a Molecular Sieve $5 \AA$ column. Nitrogen $(99.999 \%)$, further purified by passing through a nitrogen purifier (ALL-Pure Nitrogen Purifier, Alltech), was used as the carrier gas. The sample loop size was $10 \mathrm{ml}$. The air was dried prior to injection with a Nafion dryer (Permapure MD-110-72SS). Air samples were measured every $30 \mathrm{~min}$ and were bracketed by working standard measurements. This system was found to be linear for CO based on a dilution experiment as described below.

\subsubsection{GC/HgO-reduction detector: trace analytical RGA-3}

The RGA-3 gas chromatographic analysis is based on mercuric oxide reduction and ultraviolet light detection. Details of the modifications to the original setup design can be found in Vollmer et al. (2007). Chromatographic separation was achieved isothermally at $105^{\circ} \mathrm{C}$ by means of Unibeads 1 $\mathrm{S}\left(1 / 8^{\prime \prime} \mathrm{OD}, 80 \mathrm{~cm}\right)$ and Molecular Sieve $13-\mathrm{X}\left(1 / 8^{\prime \prime} \mathrm{OD}\right.$, $130 \mathrm{~cm}$ ) columns. Synthetic air, further purified with Sofnocat 514, was used as the carrier gas. The sample air and standard gases were passed through a Nafion dryer prior to injection. Instantaneous air samples were measured every $30 \mathrm{~min}$ and were bracketed by working standard measurements to determine and correct for short-term instrumental drift. The RGA-3 data were corrected for nonlinear instrument response which was characterized by dynamic dilution of a reference gas ( $1.3 \mathrm{ppm} \mathrm{CO}$ in synthetic air) with $\mathrm{CO}$ free synthetic air using two mass flow controllers and calibrated flow meters. These dilution ratios were independently checked by simultaneous analysis of $\mathrm{CH}_{4}$ on the above mentioned GC-FID, for which linearity was assumed.

\subsubsection{Calibration standards}

All measurements were traced back to a common reference standard (CA02854, 295.5 $\pm 3.0(2 \sigma)$ ppb CO in natural (ambient) air, certified NOAA/ESRL (National Oceanic and Atmospheric Administration / Earth System Research Laboratory) standard, WMO-2000 CO calibration scale). The traceability of the measurements to this standard is illustrated in Fig. 1. Table 1 gives an overview of working standards used including traceability and uncertainties. Traceability of the long-term NDIR time series to this common reference was assured by propagation of NIST SRM traceable working standards. All NIST SRMs were cross-checked against secondary standards to assure the internal consistency of the working standards.

The common WMO-2000 reference standard was regularly checked for stability against primary reference standards from NIST, NMI (Nederlands Meetinstituut) and NPL (National Physical Laboratory), along with secondary laboratory standards starting in 2000; no observable drift was found since then. A comparison of the NIST SRM 2612a 23F-06 standard against the NOAA/ESRL WMO-2000 scale through dynamic dilution showed that the NIST SRM was higher by $0.28 \pm 0.16(2 \sigma) \%$ compared to the WMO-2000 scale. This was not corrected in the data evaluation of the NDIR instrument because the difference was smaller than the certified uncertainty of the NIST standard gas; however, it has to be considered in the calculation of the uncertainty of the working standard used for the NDIR calibration. In addition, a number of comparisons of our NOAA/ESRL WMO2000 standard with other NIST standard gases (SRM 1677c, SRM 2612a 23-F-32) always showed an agreement better 
Table 1. Overview of standards used for the calibration of the CO instruments. The uncertainty for the individual standards was estimated including the traceability to the common reference (WMO-2000); the expanded uncertainty includes the uncertainty of the NOAA WMO2000 standard. All uncertainties are given for the $95 \%$ confidence level $(2 \sigma)$.

\begin{tabular}{|c|c|c|c|c|}
\hline Instrument/WS & Mole fraction (ppb) & Traceability chain & Uncert. (\%) & $\begin{array}{l}\text { Expanded } \\
\text { uncert. }(\%)\end{array}$ \\
\hline VURF / CA06439 & 438.8 & WMO-2000 & 0.3 & 1.0 \\
\hline NDIR / SL68874 & 2020.0 & NIST - WMO-2000 & 2.1 & 2.3 \\
\hline GC/FID / CC106830 & $177.9-180.0^{\mathrm{a}}$ & WMO-2000 & 0.9 & 1.4 \\
\hline $\mathrm{GC} / \mathrm{HgO} / \mathrm{E}-033$ & 241.1 & CC106830 - CA06439 - WMO-2000 & 1.7 & 2.0 \\
\hline
\end{tabular}

a A time dependent drift correction was applied

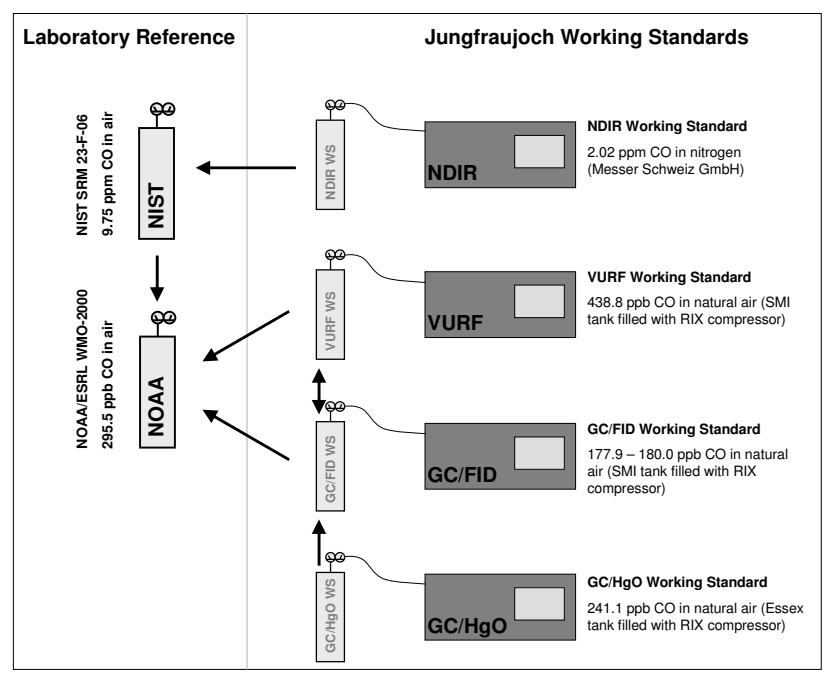

Fig. 1. Traceability of the four CO instruments to a common reference standard. The black arrows indicate the calibrations made during the inter-comparison campaign.

than $0.5 \%$ (average $0.15 \pm 0.09(2 \sigma) \%$ ), which is well within the individual stated uncertainties of the NIST SRM standards $(0.5-1.2 \%, 2 \sigma)$. Therefore the NOAA/ESRL WMO2000 scale based on this particular cylinder is not considered to be significantly different from the NIST CO scale.

Working standards were calibrated using the NOAA/ESRL and NIST laboratory standards for field calibrations at the JFJ, as illustrated in Fig. 1. The following working standards were used for the calibration of the instruments during the campaign:

NDIR - Horiba APMA 360: A 10 liter aluminum Luxfer cylinder (Messer Schweiz $\mathrm{GmbH}$ ) containing CO in nitrogen was used as a calibration gas. This cylinder was assigned $2.02 \mathrm{ppm} \mathrm{CO}$ based on initial calibration against a NIST SRM 5-I-04 (9.66 ppm CO in $\mathrm{N}_{2}$ ) in April 2005. This value was confirmed after use of the cylinder in December 2006 with NIST SRM 23-F-06 (9.75 ppm CO in air). The uncertainty of the NDIR working standard due to calibration was estimated to be $\pm 2.3 \%(2 \sigma)$ from the inter-comparison between the NOAA/ESRL and NIST reference standards $(0.56 \%, 2 \sigma)$, the contribution of an imperfect calibration on the laboratory NDIR system due to instrument noise of $12 \mathrm{ppb}$ at zero and $16 \mathrm{ppb}$ at span $(2.0 \%, 2 \sigma)$, and the uncertainty of the NOAA/ESRL standard $(1 \%, 2 \sigma)$.

VURF - Aerolaser AL5001: A 301 Scott Marrin aluminum cylinder (Luxfer) containing pressurized ambient air (RIX SA-3 oil free compressor) was used as a calibration gas. This standard was calibrated several times against the NOAA/ESRL certified standard (CA02854, $295.5 \pm 3.0(2 \sigma) \mathrm{ppb}$ CO in natural (ambient) air, WMO-2000 scale) before and after the campaign, and was assigned a $\mathrm{CO}$ mole fraction of $438.8 \mathrm{ppb}$. No significant drift was observed in this cylinder over its lifetime between July 2005 and September 2006. The uncertainty of the VURF working standard was estimated to be $1.0 \%(2 \sigma)$ based on multiple calibrations against the NOAA/ESRL standard. Note that the VURF instrument requires a standard in natural air because the UV fluorescence reaction is quenched by oxygen. No matrix effects for standards balanced with air or nitrogen are known for the other analytical techniques.

GC/FID: A working standard with the same cylinder type and material as the one for the Aerolaser instrument was used for automatic calibrations; however, $\mathrm{CO}$ in this cylinder was less stable, and a continuous and constant upward drift of $\mathrm{CO}$ was observed over time. The cylinder was calibrated against the NOAA/ESRL certified standard described above several times before and after the campaign, and against the working standard of the VURF instrument during the campaign. Based on these measurements, a linear correction was applied, with a $\mathrm{CO}$ increase rate of $0.033 \mathrm{ppb}$ per day and an initial mole fraction of $172.0 \mathrm{ppb}$ on 15 July 2005 . This allowed the calculation of the working standard mole fractions at all times during the campaign. The estimated uncertainty of this standard is $1.4 \%(2 \sigma)$ from a linear interpolation of multiple calibrations against the NOAA/ESRL standard.

GC/HgO: An electro-polished stainless steel tank (Essex Cryogenics) filled with natural ambient air was used as a working standard. This standard was stable at $241.1 \mathrm{ppb}$ CO 

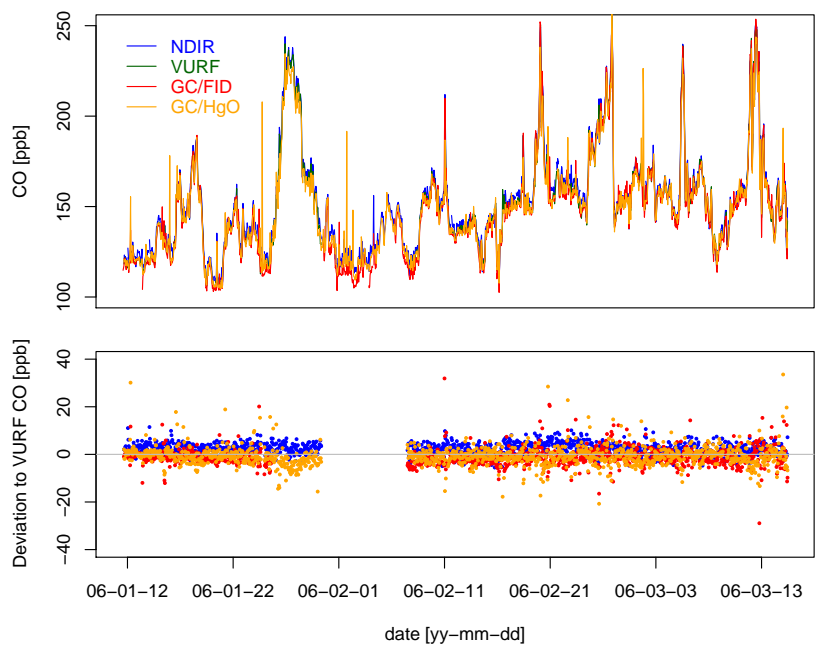

Fig. 2. Time series of one-hourly averages for all four CO instruments (upper panel) and difference between the NDIR and GC techniques to the VURF instrument (lower panel).

for the period of the campaign. The standard was referenced against the standard of the GC/FID instrument. The uncertainty of the standard was estimated to be $2.0 \%(2 \sigma)$.

\section{Results and discussion}

\subsection{Field inter-comparison}

Measurements with four $\mathrm{CO}$ instruments employing four different analytical techniques were performed over a period of approximately two months between 11 January and 15 March 2006. Data availability based on one-hourly averages was $96.7 \%$ (NDIR), 86.4\% (VURF), 86.7\% (GC/FID), and $98.9 \%(\mathrm{GC} / \mathrm{HgO})$. For the continuous techniques, onehourly averages were only calculated when at least four 10min averages were available. Hourly averages of the GC observations typically represent the average of two single injections. Figure 2 shows the available time series for all four techniques and the difference between the NDIR / GC techniques and the VURF instrument. The overall variability was well captured by all techniques. The $\mathrm{CO}$ mole fractions during the campaign ranged from approximately 100 to $260 \mathrm{pb}$, which is consistent with other studies at the JFJ site (Forrer et al., 2000; Zellweger et al., 2003). Figure 2 shows that the NDIR results were slightly higher throughout the entire campaign, with an almost constant bias irrespective of the $\mathrm{CO}$ level. However, the deviations of the NDIR from the VURF results seem to decrease slightly towards the end of the intercomparison. The reason for this may be changing NDIR zero readings during the campaign. Figure 3 shows the individual zero readings of the NDIR instrument (1-min averages) made automatically every $49 \mathrm{~h}$, as well as the corresponding $30 \mathrm{~min}$ averages. These zero readings averaged $-0.3 \pm 8.4(2 \sigma) \mathrm{ppb}$

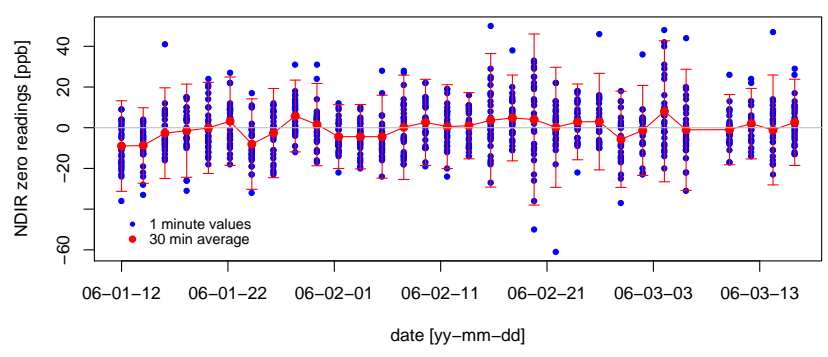

Fig. 3. Automatic zero checks of the NDIR instrument. The blue circles represent 1-min averages and the red dots the corresponding 30 -min average. The error bars represent the expanded uncertainty $(2 \sigma)$ of the 30 -min average.

and were not significantly different from zero over the entire period. Consequently, due to the relatively high uncertainties of the individual zero readings, no further correction was applied to the data. However, neither a potential drift nor an offset can be excluded based on these data, which potentially explains the small observed difference.

Table 2 shows the parameters obtained from orthogonal regression analysis (York, 1966) between different techniques based on one-hourly averages. A generally good agreement was found among all techniques, with the highest correlation between the two continuous methods (VURF and NDIR, $\left.r^{2}=0.992\right)$. A slightly lower but still excellent correlation was found between the continuous and the GC methods $\left(r^{2}\right.$ between 0.962 and 0.981 ), while the lowest correlation was observed between the two GC methods (GC/FID and GC/HgO, $r^{2}=0.935$ ). Due to the large number of measurement points, the estimated uncertainties of slope and intercept were relatively small, and significant differences were found between all time series. A pair-wise Wilcoxon-Mann-Whitney test based on one-hourly averages also confirmed significant differences between all possible combinations ( $p$-value $<0.01$ with Bonferroni correction for multiple testing), with the exception of the VURF-NDIR instrument pair ( $\mathrm{p}$-value $=0.42$ ). These results suggest that the differences observed by Whalley et al. (2004) between the JFJ NDIR system and their VURF instrument of $20-30 \mathrm{ppb}$ are likely due to the use of calibration standards that were not traceable to NIST or WMO-2000 CO scales, or from instrumental faults, such as leaks.

The agreement between the various time series is further illustrated in relative difference histograms (Fig. 4) compared to the VURF as the reference instrument for averages of $1-, 10-$, and $60 \mathrm{~min}$ respectively. Single injections of the GC techniques were compared to $1 \mathrm{~m}$-in and $10 \mathrm{~min}$ data, and the average of (usually) 2 GC injections was used to compare with for hourly averages. The relative differences $\left(x-x_{\text {ref }}\right) / x_{\text {ref }}$ are shown where $x_{\text {ref }}$ is the CO mole fraction measured by the reference instrument (VURF). In addition, the individual uncertainties of the calibration standards (cf. 
Table 2. Results of the orthogonal regression analysis between the different measurement techniques, where $\mathrm{x}$ and $\mathrm{y}$ are the corresponding instruments, and $\mathrm{a}$ and $\mathrm{b}$ are the intercept and slope of the regression line with $95 \%$ confidence intervals. $r^{2}$ is the coefficient of determination, and $\mathrm{N}$ is the number of data points. In addition, the p-value of the Wilcoxon-Mann-Whitney test is shown. Comparisons are based on onehourly averages.

\begin{tabular}{llrrrrr}
\hline $\mathrm{y}$ & $\mathrm{x}$ & $\mathrm{a}[\mathrm{ppb}]$ & $\mathrm{b}$ & $\mathrm{r}^{2}$ & $\mathrm{~N}$ & $\mathrm{p}$-value \\
\hline VURF & NDIR & $-1.9 \pm 0.8$ & $0.997 \pm 0.005$ & 0.992 & 1273 & 0.424 \\
VURF & GC/FID & $6.1 \pm 1.2$ & $0.967 \pm 0.008$ & 0.981 & 1165 & $3.95 \mathrm{e}-12$ \\
VURF & GC/HgO & $-4.4 \pm 1.5$ & $1.033 \pm 0.010$ & 0.970 & 1292 & $4.03 \mathrm{e}-04$ \\
NDIR & GC/FID & $9.8 \pm 1.3$ & $0.960 \pm 0.009$ & 0.975 & 1271 & $3.19 \mathrm{e}-10$ \\
NDIR & GC/HgO & $-2.0 \pm 1.6$ & $1.033 \pm 0.010$ & 0.962 & 1448 & $1.50 \mathrm{e}-05$ \\
GC/FID & GC/HgO & $-1.2 \pm 2.2$ & $1.070 \pm 0.016$ & 0.935 & 1299 & $2.41 \mathrm{e}-03$ \\
\hline
\end{tabular}

Table 1) and the additional uncertainty due to imperfect zero compensation of the NDIR instrument are shown. The maximum of the distribution of the differences was in all cases within the uncertainty limits of the calibration standards. It can therefore be concluded that the mean differences of the various time series are due to differences in the calibration standards. It can further be seen that the averaging time has a significant influence on the width of the relative difference distribution for the NDIR technique. The standard deviation of the relative difference distribution is comparable for all techniques for one-hourly averages, with the lowest value for the NDIR technique. This implies that the performance of the NDIR technique for one-hourly averages is equal or even slightly better compared to the GC methods. At the 10 min level the noise of the NDIR technique was significant, but the performance was still comparable to the GC techniques. The GC techniques showed a considerable number of values with large deviation compared to the VURF method, resulting in long tails of the distribution of the relative differences at the $1-$ and 10 min levels; this can be explained with the different temporal coverage was different (single injections vs. integration over ten $\mathrm{min}$ ). The number of these outliers was relatively insensitive to the level of aggregation, but the overall width of the frequency distribution increased slightly due to the fact that instrument noise was becoming more of an issue. This was also the case for the VURF technique. Instrument noise was clearly the dominating factor for the NIDR technique on the 1 min level. The width of the distribution of the $1 \mathrm{~min}$ relative differences of the NDIR technique was comparable to data obtained from our laboratory experiments with a Horiba APMA-360 NDIR $\mathrm{CO}$ monitor. This was demonstrated through an additional experiment, during which the $1 \mathrm{~min}$ average noise over $24 \mathrm{~h}$ was determined at a constant mole fraction of $152 \mathrm{ppb}$, which is similar to the average mole fraction during the JFJ campaign. Based on this experiment a standard deviation of the relative difference for a mole fraction of $152 \mathrm{ppb}$ of 0.0750 was calculated during the laboratory experiment compared to 0.0768 during the JFJ campaign. For the $10 \mathrm{~min}$ and hourly averages, the corresponding numbers were $0.0336(0.0310$ at JFJ), and 0.0208 ( 0.0171 at JFJ). This clearly demonstrates that instrument noise is a limiting factor for the determination of CO levels with the NDIR technique if high temporal resolution is required. It can be seen from Fig. 4 that the averaging interval has a significant influence on the uncertainty of the NDIR measurements. One-hourly averages of the NDIR instrument achieve a data quality that is comparable to the GC instruments, with even slightly lower relative differences because of fewer outliers. This is confirmed by the Wilcoxon-Mann-Whitney test, which also does not yield significant differences between the NDIR and the GC techniques when one-hourly averages are compared.

The mean value of the relative difference is a measure of the difference in location of the data points compared to the VURF technique. The largest mean deviation $(1.58 \%)$ was observed between the VURF and NDIR technique. However, the calibration standard of the NDIR instrument also has a relatively high uncertainty, and at least part of the bias can be explained by differences in the calibration. In addition, imperfect compensation of the zero offset (cf. Fig. 3) may also contribute to the observed bias. Automatic zero checks were made every $49 \mathrm{~h}$, which is potentially insufficient for an accurate compensation of the zero offset. The standard deviation of the zero readings obtained during the campaign was $4.2 \mathrm{ppb}$ (31 observations); this results in an additional uncertainty of the NDIR measurements of $1.0 \%$.

To illustrate the performance as a function of the averaging time, a selected time period is shown in Fig. 5. During the period from 11 to 13 March, rapid changes in the ambient mole fractions occurred. Instrument noise of the NDIR technique was dominant at the one minute level, but good agreement was observed between all techniques for $10 \mathrm{~min}$ and one-hourly averages. All instruments were able to detect fast changes in the $\mathrm{CO}$ mole fractions that occurred in the second half of the selected period. More interesting is the first half of the period that was characterized by relatively small changes of the mole fractions. Part of this period was characterized by large short-term variations as apparent from 

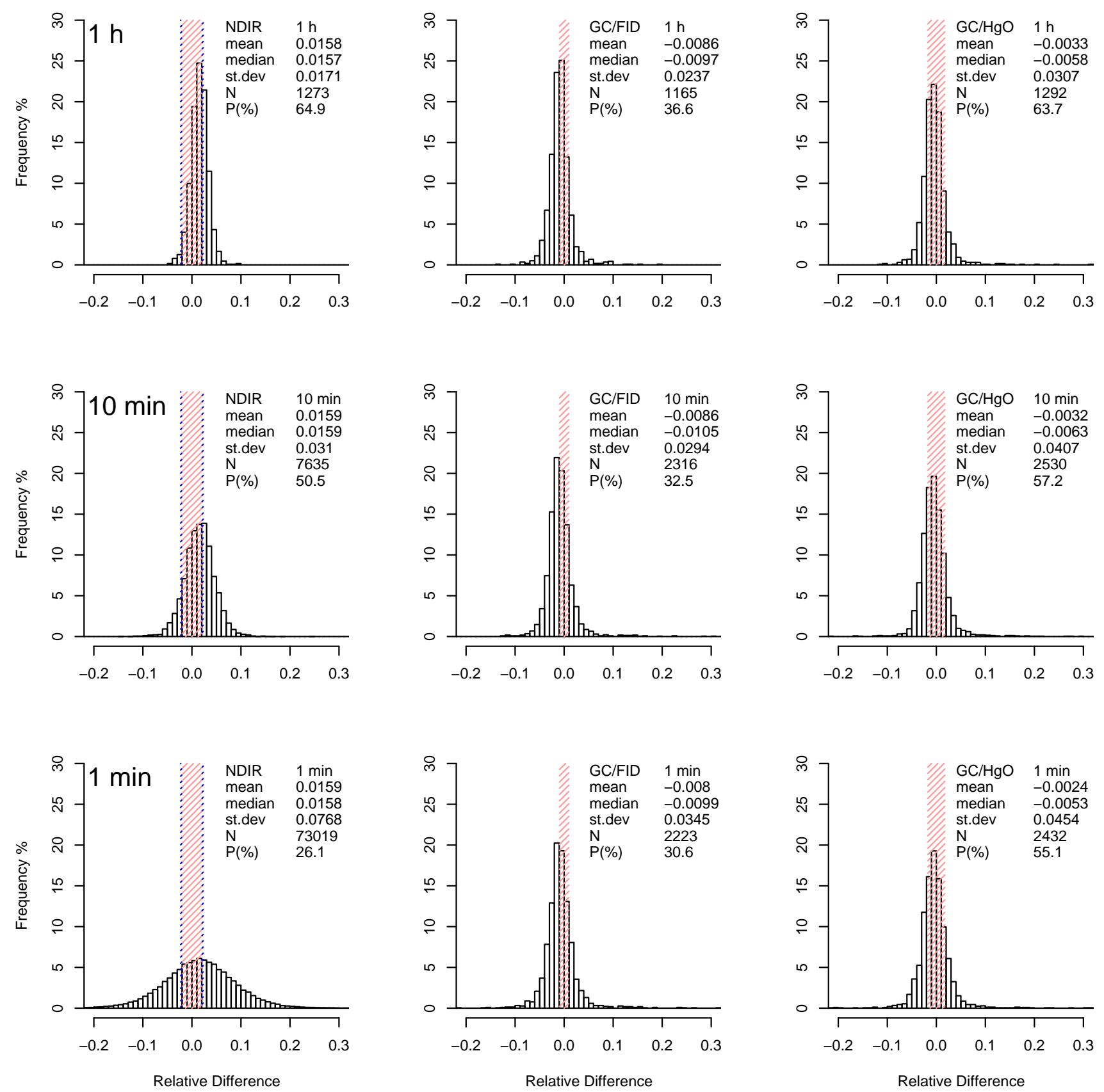

Fig. 4. Relative difference histograms for the NDIR and GC instruments calculated relative to a common reference instrument (VURF). Each panel shows the frequency of data falling into 0.01 relative difference bins (normalized to the number of coincident data points). Relative differences for one-hourly, 10-min and 1-min averages are shown. 1- and 10-min averages of the GC techniques represent single injections. The red shaded areas represent the uncertainty of the calibration standards, and the blue shaded areas the uncertainty due to imperfect zero compensation (NDIR only). $\mathrm{P}(\%)$ is the percentage of data falling within the uncertainty limits.

the one minute VURF data. These fast changes could only be detected with the VURF technique because the instrument noise of the NDIR monitor is too large to allow detection of mole fraction changes of a few ppb on a temporal scale ranging from seconds to a few minutes. The GC techniques were able to accurately reflect the $\mathrm{CO}$ mole fraction, but lack temporal resolution; consequently, differences of integrated values between continuous and GC methods may be significantly higher compared to periods with less pronounced short-term variation in the $\mathrm{CO}$ mole fractions. The period 

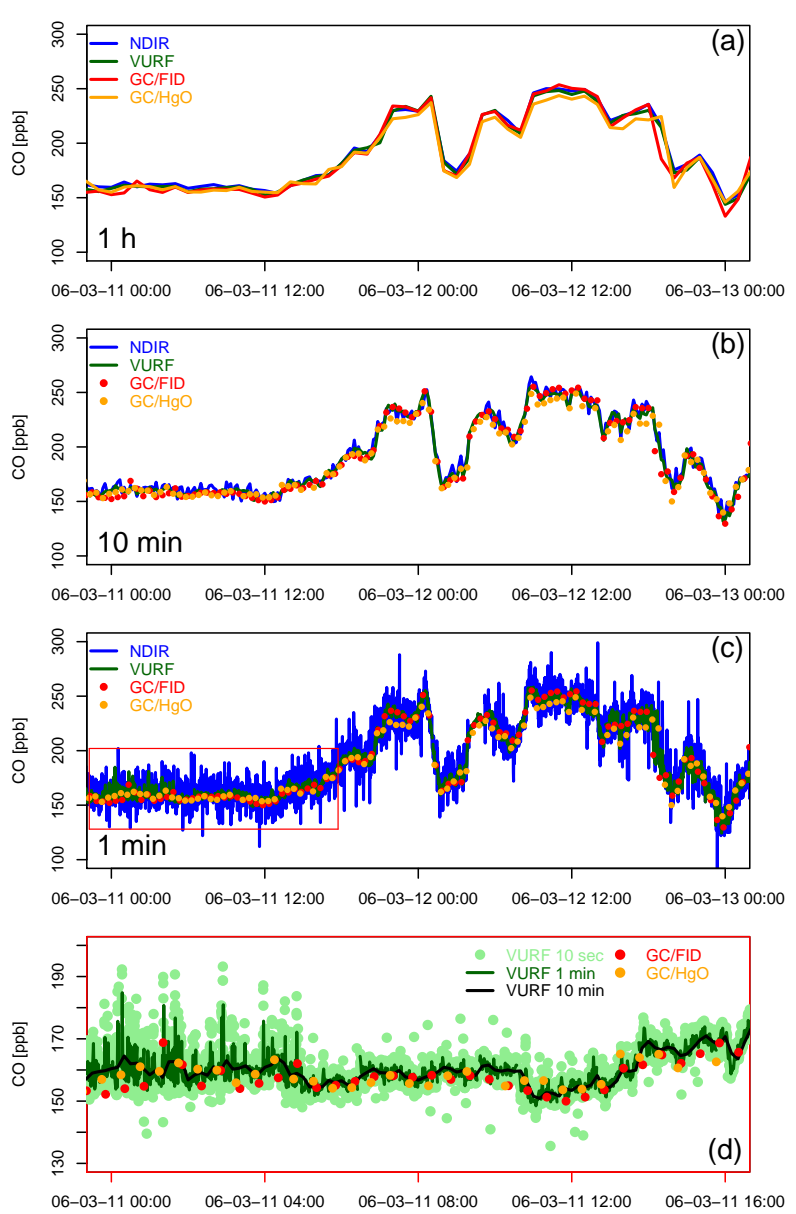

Fig. 5. CO time series with all four techniques for a selected period in March 2006, for (a) one-hourly averages, (b) $10 \mathrm{~min}$ averages (VURF, NDIR)/single injections (GC), (c) 1-min averages (VURF, NDIR)/single injections (GC), and zoomed in period (d) including $10 \mathrm{~s}$ VURF data.

with pronounced short-term variability is further highlighted in Fig. 5d. In the first six hours of the selected period significant short-term variability in the $\mathrm{CO}$ mole fractions was observed, which is visible in the VURF 1 min and $10 \mathrm{~s}$ averages. During this period, the agreement between the $10 \mathrm{~min}$ VURF average and the single GC injections was considerably lower compared to the following hours with more stable $\mathrm{CO}$ mole fractions. The lack of temporal coverage of the GC methods explains to a large extent the lower correlation between the quasi-continuous and continuous techniques. In conclusion, one-hourly NDIR CO data of the JFJ station can be considered to be fully comparable to data obtained with a VURF.
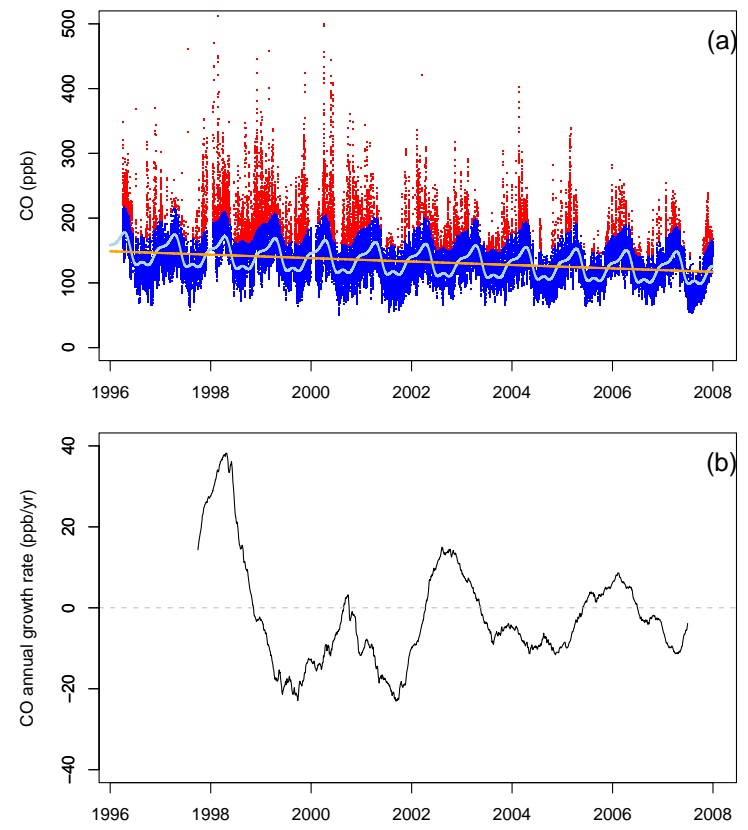

Fig. 6. (a) JFJ CO time series (one-hourly data) from 1996 to 2007. The light blue curve represents a fitted baseline and the orange line the linear trend of the baseline data. Blue points correspond to baseline data, and red points to pollution events (see text for details). (b) $\mathrm{CO}$ annual growth rate calculated as the difference between two annual moving averages (see text for details).

\subsection{Carbon monoxide trend at Jungfraujoch between 1996 and 2007}

The JFJ carbon monoxide time series is one of the longest continuous datasets of $\mathrm{CO}$ measurements in the remote continental troposphere in Europe. Figure 6a shows the 12-year CO time series from 1996 to 2007 of JFJ obtained with NDIR instruments as described in the previous section, and a summary of monthly and yearly mean mole fractions is shown in Table 3. To investigate trends and seasonal behavior, the onehourly $\mathrm{CO}$ data were decomposed into a quadratic trend and average seasonal cycle as shown in Eq. (1) (Thoning et al., 1989). This function has been successfully used to determine the long-term trend of baseline data from the NOAA/ESRL flask sampling network (Novelli et al., 1998; Novelli et al., 2003).

$$
\begin{aligned}
f(t)= & a_{1}+a_{2} t+a_{3} t^{2} \\
& +\sum_{i=1}^{4}\left[a_{(2 i+2)} \sin (2 \Pi i t)+a_{(2 i+3)} \cos (2 \Pi i t)\right]
\end{aligned}
$$

The complete fit including the seasonal variation (light blue line) and a linear trend (orange line, see below) are also plotted in Fig. 6a. In addition, individual data points were discriminated between baseline conditions (blue) and pollution (red) events. These events were defined by assuming normal distribution of baseline values around the fitted function. To 
define conditions for pollution events, the negative residuals of the fit were first mirrored at zero. The standard deviation of the distribution of negative residuals and mirrored negative residuals was then used to calculate the condition for pollution events. Values higher by more than two standard deviations were considered as pollution events. The annual growth rate curve is plotted in Fig. 6b. The growth rate was calculated as the difference between two annual moving averages based on daily data. To avoid a bias in the growth rate due to missing values, a loess fit was applied to the data and gaps were filled with predicted data based on the fitting parameters. For better comparability of the growth rate with ambient data presented in Fig. 6a, the growth rate values are centered on the time axis such that, for example, the value of 1 July 1999 represents the growth rate for the period from 1 January 1999 thru 31 December 1999.

It can be seen that the $\mathrm{CO}$ mole fractions decreased significantly during the period between 1996 and 2007. The trend part of the fit is close to linear with a fitted value of $\mathrm{a}_{3}=0.050 \pm 0.014$. Due to the small contribution of the non-linear term $\mathrm{a}_{3} \mathrm{Eq}$. (1) was simplified by setting $\mathrm{a}_{3}=0$ to calculate the linear baseline CO trend at JFJ (orange line in Fig. 6a). The result is an average change of $-2.65 \pm 0.04 \mathrm{ppb} / \mathrm{yr}$, which corresponds to a decrease in baseline CO of $21.4 \%$ over the period 1996 to 2007 at JFJ.

The average and seasonal diurnal cycles of mean $\mathrm{CO}$ mole fractions are shown in Fig. 7a. A significant diurnal cycle with lowest values in the early morning and maximum values in late afternoon local time could only be observed during the warmer seasons (spring and summer). This is in line with observations from previous studies that documented the influence of more polluted atmospheric boundary layer air lifted by thermally induced flow systems (Forrer et al., 2000; Zellweger et al., 2003; Henne et al., 2004). It can also be seen from the yearly seasonal cycles (Fig. 7b) that the $\mathrm{CO}$ mole fraction decreased over the observation period, and reached its lowest values during summer 2007. Part of this inter-annual variability can be explained by global biomass burning. Elevated CO mole fractions were observed during periods with increased biomass burning, e.g. 1996 and 1998 (Yurganov et al., 2004; Wotawa et al., 2001), and also for the years 2002 and 2003 (Yurganov et al., 2005). These events are well captured by the growth rate as illustrated in Fig. 6b. However, elevated mole fractions during the summer of 2003 may also be explained by increased thermally induced vertical upward transport due to the extremely high Central European summer temperatures in 2003 and the forest fires in Portugal (Luterbacher et al., 2004; Tressol et al., 2008). Despite significant year-to-year variability, the trend over the observation period was rather constant and no significant seasonality was observed in the decrease (not shown). An analysis of the monthly JFJ data showed that the decrease was significantly lower for February and March at approx. $-1.2 \mathrm{ppb} / \mathrm{yr}$ for both months. This observation is in line with a model study by Pfister et al. (2004) showing the
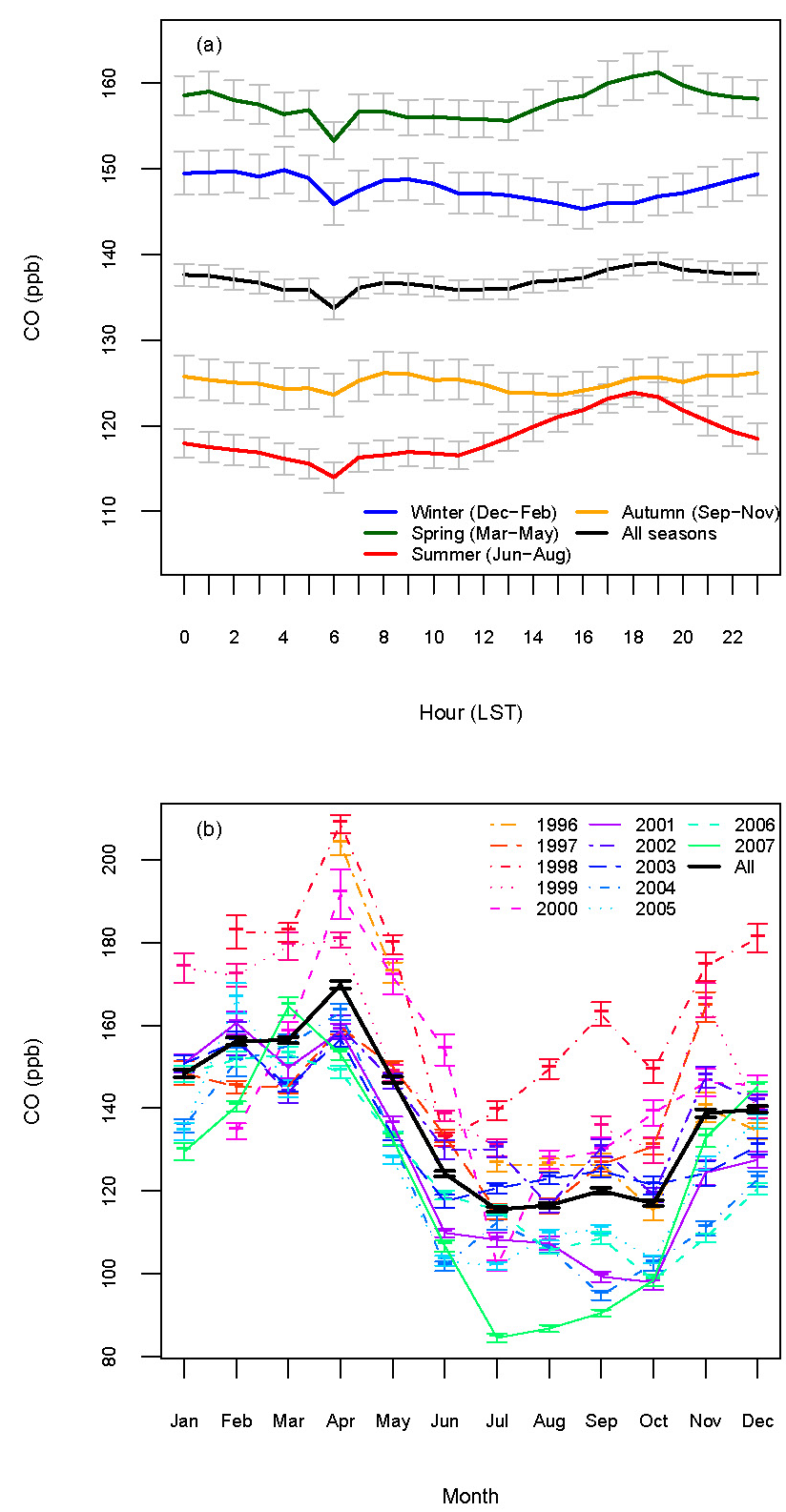

Fig. 7. (a) Average and seasonal diurnal cycles of mean CO mole fractions of the years 1996 to 2007 at JFJ. (b) Mean CO annual cycle per year. Monthly means are only shown if the data availability exceeds $75 \%$. The error bars represent the expanded standard uncertainty.

largest contributions of Asian and North American anthropogenic CO in Europe between January and May. However, it is in contrast to observations at Zugspitze (ZUG) (Chevalier et al., 2008), where the overall annual downward trend was mainly attributed to a decrease in the winter / spring period (January-April). Furthermore, the magnitude of the $\mathrm{CO}$ decrease is significantly higher at JFJ $(-2.65 \pm 0.04 \mathrm{ppb} / \mathrm{yr}$, 1996-2007) when compared with ZUG (-0.84 ppb/yr,19912004) (Chevalier et al., 2008). It should also be noted that the 
Table 3. Monthly and yearly mean CO mole fractions (ppb) at Jungfraujoch for the years 1996 to 2007. Monthly mean values were only calculated if at least $75 \%$ of the data where available. Yearly averages were only calculated if the data coverage was larger than $90 \%$.

\begin{tabular}{lrrrrrrrrrrrrr}
\hline $\begin{array}{l}\text { Month } \\
\text { Year }\end{array}$ & 1 & 2 & 3 & 4 & 5 & 6 & 7 & 8 & 9 & 10 & 11 & 12 & AVG \\
\hline 1996 & NA & NA & NA & 203.7 & NA & 162.2 & 126.4 & 126.2 & 126.4 & 115.4 & 140.2 & 134.5 & NA \\
1997 & 148.5 & 145.2 & 145.3 & 159.5 & 150.0 & 133.3 & 115.1 & 116.4 & 126.4 & 130.8 & 164.4 & NA & NA \\
1998 & 197.1 & 182.6 & 182.5 & 208.6 & 179.5 & 132.5 & 139.3 & 149.4 & 162.7 & 148.9 & 174.3 & 181.0 & 168.9 \\
1999 & 173.8 & 172.1 & 179.2 & 180.6 & 148.5 & 138.2 & 130.5 & NA & 135.3 & 129.9 & 166.1 & 139.1 & 153.2 \\
2000 & NA & 134.4 & 158.1 & 191.8 & 171.8 & 154.1 & 102.0 & 127.6 & 129.6 & 138.9 & 146.2 & 145.6 & NA \\
2001 & 150.8 & 160.6 & 149.8 & 158.6 & 136.1 & 109.9 & 108.2 & 107.4 & 99.3 & 98.0 & 124.4 & 127.5 & 127.3 \\
2002 & NA & 156.9 & 143.6 & 159.5 & 146.6 & 130.0 & 130.1 & 116.4 & 130.4 & 119.1 & 147.5 & 141.5 & 137.8 \\
2003 & 150.8 & 156.1 & 145.2 & 156.6 & 133.3 & 117.5 & 120.7 & 123.0 & 124.8 & 121.4 & 124.3 & 130.8 & 133.7 \\
2004 & 135.7 & 151.2 & 155.1 & 163.2 & 132.3 & 101.8 & 112.4 & 106.2 & 94.8 & 102.4 & 111.0 & 122.8 & 124.2 \\
2005 & 134.3 & 166.6 & 144.8 & NA & 127.6 & 103.2 & 101.8 & 109.4 & 110.8 & 103.6 & 126.7 & 136.8 & 126.0 \\
2006 & 148.3 & 151.8 & 153.0 & 148.7 & 132.7 & 119.0 & 115.4 & 105.6 & 108.6 & 98.5 & 108.7 & 120.5 & 125.7 \\
2007 & 129.5 & 140.4 & 164.6 & 153.0 & 132.5 & 106.7 & 84.5 & 86.8 & 90.5 & 98.4 & 132.8 & 145.2 & 121.9 \\
\hline AVG & 148.4 & 156.1 & 156.5 & 169.8 & 146.9 & 124.2 & 115.5 & 116.5 & 120.1 & 117.0 & 138.8 & 139.7 & \\
\hline
\end{tabular}

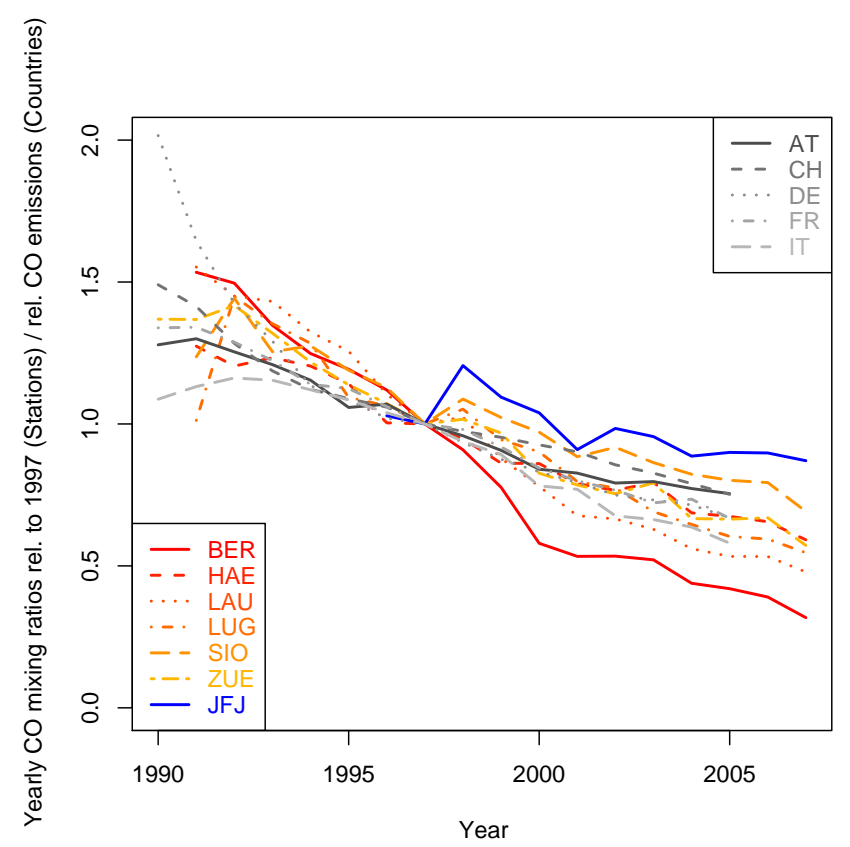

Fig. 8. Emissions reported to the Long-range Transboundary Air Pollution (LRTAP) Convention (EMEP) normalized to 1997 for Switzerland and neighboring countries (grey colors), and yearly mean CO mole fractions normalized to 1997 for JFJ and other sites in Switzerland (see text for details).

trend at JFJ was calculated using baseline data, whereas the trend at ZUG was estimated without data filtering. Using the same method (linear fit through all data) results in an even larger annual decrease of $-3.32 \pm 0.07 \mathrm{ppb}$ at JFJ, which is higher by a factor of 4 compared to the decrease at ZUG.
These differences are difficult to explain, but may be due to a difference in air mass origin measured at the two sites. For example, pollution from the Po Valley was identified to have a significantly greater influence on JFJ compared to ZUG based on back trajectory analysis (Kaiser et al., 2007).

The observed overall negative trend of $\mathrm{CO}$ at JFJ can mainly be explained by the reduction of European emission sources since the early 1990s. Fossil fuel emissions are the largest contributor to the $\mathrm{CO}$ burden in the northern extratropics (Duncan et al., 2007). European CO emissions of the EU-15 member states decreased from $39.1 \mathrm{Gt}$ in 1996 to $24.2 \mathrm{Gt}$ in 2005 (EEA, 2007), which corresponds to a decrease of $38.1 \%$. During the same period the measured CO mole fraction at JFJ decreased by $17.8 \%$, which is less than half of what would be expected if only European emissions were contributing to the CO levels observed at JFJ. A comparison of emission inventory data with $\mathrm{CO}$ measurements from sites situated at lower altitudes in Switzerland is shown in Fig. 8. Emission data were taken from the reports to the Long-range Transboundary Air Pollution (LRTAP) Convention (EEA, 2007). Yearly mean values of both station and emission inventory data were normalized to 1997. CO mole fractions decreased most at two curbside sites Bern (BER) and Lausanne (LAU). The agreement with the emission inventory data is very good if only road transportation emissions are considered (not shown). Data of the emission inventory also agree well with measured $\mathrm{CO}$ mole fractions at the two urban sites, Lugano (LUG) and Zürich (ZUE), as well as the two rural sites, Härkingen (HAE) and Sion (SIO), which are both situated adjacent to a highway and thus highly influenced by traffic emissions. The observations at these stations seem to be representative for European CO emission trends and reliably represent the mixture of traffic and 
industrial emissions. The trend at JFJ is significantly lower compared to the other sites and the inventory data. In addition, global scale events such as increased biomass burning in 1998 are clearly visible in the JFJ data. A possible reason for the lower decrease at JFJ is long-range transport of $\mathrm{CO}$ from regions where emissions have not decreased in proportion to European emissions. The lifetime of $\mathrm{CO}$ is long enough to allow transport over long distances. For example, several model studies indicate that fossil and biofuel CO sources from Asia are significantly underestimated (Duncan et al., 2007). Tanimoto et al. (2008) suggested an increase of 16\% of the CO emissions in China between 2001 and 2005. Part of the smaller CO decrease at JFJ could also be explained by oxidation of $\mathrm{CH}_{4}$ and non-methane hydrocarbons (NMHC). Holloway et al. (2000b) found that $\mathrm{CH}_{4}$ oxidation provides a uniform $\mathrm{CO}$ background of about $25 \mathrm{ppb}$ in the troposphere. The oxidation of other biogenic hydrocarbons also contributes to global $\mathrm{CO}$, but provides a smaller source compared to $\mathrm{CH}_{4}$ oxidation. Holloway et al. (2000b) estimated the biogenic NMHC contribution to be $90 \%$ compared to $\mathrm{CH}_{4}$, whereas Duncan et al. (2007) calculated it to be between $41-51 \%$. Based on these data, we estimate a contribution of 35-48 ppb $\mathrm{CO}$ due to oxidation of $\mathrm{CH}_{4}$ and biogenic NMHC. If we subtract this contribution from our JFJ dataset a decrease in baseline $\mathrm{CO}$ of -23.3 to $-26.3 \%$ is calculated from 1996 to 2005. Based on a comparison with emission inventory data (38.1\% decrease), the fraction of air influenced by source regions outside EU-15 Europe is larger than one third. This is in agreement with a study using chemical transport models (Pfister et al., 2004) to evaluate the origin of $\mathrm{CO}$ over Europe. Pfister et al. (2004) showed that the annual mean contribution to anthropogenic $\mathrm{CO}$ mole fractions for some source regions over Europe is highly dependent on altitude. Their model estimated significant contributions to anthropogenic CO from source regions in Asia $(\sim 35 \%)$, NorthAmerica $(\sim 30 \%)$, Europe $(\sim 25 \%)$, and North-Africa $(\sim 5 \%)$ at the $660 \mathrm{hPa}$ level (corresponding to JFJ altitude), whereas intrusions from other regions were found to be negligible. In addition, a seasonality with largest contributions of Asian and North American anthropogenic CO to Europe between January and May was observed (Pfister et al., 2004). Therefore, Asian emissions may offset the $\mathrm{CO}$ trend in the free continental troposphere over Europe, and are the most likely reason for the relatively low CO decrease at JFJ compared to lower-elevation sites in Europe. This has to be considered when $\mathrm{CO}$ is used in combination with emission inventory data for source allocation and emission quantification. These long-range transport effects are likely altitude dependent and play a more important role in the upper troposphere. Dils et al. (2009) derived long-term trends at JFJ from remote sensing ground-based FTIR measurements in the altitude range from the elevation of JFJ to $7 \mathrm{~km}$ and found a negative trend of only about $1 \mathrm{ppb}$ per year for the 1997 to 2005 period. This could potentially be explained by an altitude dependency on air mass origin, with long-range transport becoming more important at higher altitudes. No significant trend was observed from MOPITT retrievals at $700 \mathrm{hPa}$ on average over a $1500 \mathrm{~km}$ radius area over Western Europe (Chevalier et al., 2008). However, satellite data capture a larger area and altitude range, and results are therefore not always directly comparable to in-situ measurements.

\section{Conclusions}

An inter-comparison between four different measurements techniques (NDIR, VURF, GC/FID, and $\mathrm{GC} / \mathrm{HgO}$ ) for the measurement of atmospheric $\mathrm{CO}$ showed excellent agreement among all analytical techniques based on one-hourly averages. The observed differences could be explained with remaining biases of calibration standards. Thus, when other potential issues such as non-linearity are carefully considered in the measurement set-up, the limiting factor for accurate $\mathrm{CO}$ measurements is the uncertainty of the calibration standards. In addition, the NDIR technique requires careful zero compensation to achieve data of sufficiently high quality.

The inter-comparison demonstrated that the cross flow modulation NDIR technique provides reliable data on an hourly basis and is well suited for CO measurements even at remote sites; however, data with higher temporal resolution must be interpreted with caution. It should further be noted that other instruments using gas filter correlation techniques were not tested in the current inter-comparison study.

The inter-comparison experiment added to the validation of the 12 year long CO time series made by NDIR technique at the JFJ. Results show a clear decrease of the CO burden over Europe during the past decade, which is in agreement with decreasing $\mathrm{CO}$ emissions in Europe. Further examination of this time series showed that CO decreased by $21.4 \%$ in the period from 1996 to 2007 at JFJ. This trend fits well into the context of decreasing $\mathrm{CO}$ emissions in Europe. However, comparisons with emission inventory data showed that a significantly larger decrease would be expected if European emissions alone were driving $\mathrm{CO}$ mole fractions at JFJ. Therefore, long-range transport is considered to have a significant influence on the CO levels at JFJ. It was estimated that a least one third of the baseline $\mathrm{CO}$ measured at JFJ is of non-European origin after considering the fraction of $\mathrm{CO}$ produced by $\mathrm{CH}_{4}$ and NMHC oxidation. This is in agreement with model studies that attribute a significant fraction of the European CO budget to non-European sources (Pfister et al., 2004).

Acknowledgements. The authors would like to thank the International Foundation Jungfraujoch and Gornergrat and the custodians at the JFJ Research Station for their support and hospitality. Parts of the measurements were made by the Swiss National Air Pollution Monitoring Network (NABEL) in collaboration with the Swiss Federal Office for the Environment (FOEN). The work was also supported by MeteoSwiss through engagement in the Global Atmosphere Watch programme. 
Edited by: A. Hofzumahaus

\section{References}

Chevalier, A., Gheusi, F., Attié, J. L., Delmas, R., Zbinden, R., Athier, G., and Cousin, J. M.: Carbon monoxide observations from ground stations in France and Europe and long trends in the free troposphere, Atmos. Chem. Phys. Discuss., 8, 3313-3356, 2008 ,

http://www.atmos-chem-phys-discuss.net/8/3313/2008/.

Daniel, J. S. and Solomon, S.: On the climate forcing of carbon monoxide, J. Geophys. Res. Atmos., 103, 13249-13260, 1998.

Dils, B., Mahieu, E., Demoulin, P., Steinbacher, M., Buchmann, B., and De Maziere, M.: Ground-based CO observations at Jungfraujoch: Comparison between FTIR and NDIR measurements, in preparation, 2009.

Duncan, B. N., Logan, J. A., Bey, I., Megretskaia, I. A., Yantosca, R. M., Novelli, P. C., Jones, N. B., and Rinsland, C. P.: Global budget of CO, 1988-1997: Source estimates and validation with a global model, J. Geophys. Res. Atmos., 112, D22301, doi:10.1029/2007JD008459, 2007.

EEA: Annual European Community LRTAP Convention Emission Inventory report 1990-2005, Technical report No 14/2007, EEA (European Environment Agency)14/2007, 2007.

Folini, D., Ubl, S., and Kaufmann, P.: Lagrangian particle dispersion modeling for the high Alpine site Jungfraujoch, J. Geophys. Res. Atmos., 113, D18111, doi:10.1029/2007jd009558, 2008.

Forrer, J., Ruttimann, R., Schneiter, D., Fischer, A., Buchmann, B., and Hofer, P.: Variability of trace gases at the high-Alpine site Jungfraujoch caused by meteorological transport processes, J. Geophys. Res. Atmos., 105, 12241-12251, 2000.

Fried, A., Henry, B., Parrish, D. D., Carpenter, J. R., and Buhr, M. P.: Intercomparison of Tunable Diode-Laser and Gas Filter Correlation-Measurements of Ambient Carbon-Monoxide, Atmos. Environ. A-Gen., 25, 2277-2284, 1991.

GAWSIS: GAW Station Information System: http:/gaw.empa.ch/ gawsis, access: May 15, 2009.

Gerbig, C., Schmitgen, S., Kley, D., Volz-Thomas, A., Dewey, K., and Haaks, D.: An improved fast-response vacuum-UV resonance fluorescence CO instrument, J. Geophys. Res. Atmos., 104, 1699-1704, 1999.

Henne, S., Furger, M., Nyeki, S., Steinbacher, M., Neininger, B., de Wekker, S. F. J., Dommen, J., Spichtinger, N., Stohl, A., and Prévôt, A. S. H.: Quantification of topographic venting of boundary layer air to the free troposphere, Atmos. Chem. Phys., 4, 497509, 2004, http://www.atmos-chem-phys.net/4/497/2004/.

Hoell, J. M., Gregory, G. L., McDougal, D. S., Sachse, G. W., Hill, G. F., Condon, E. P., and Rasmussen, R. A.: Airborne Intercomparison of Carbon-Monoxide Measurement Techniques, J. Geophys. Res. Atmos., 92, 2009-2019, 1987.

Holloway, J. S., Jakoubek, R. O., Parrish, D. D., Gerbig, C., VolzThomas, A., Schmitgen, S., Fried, A., Wert, B., Henry, B., and Drummond, J. R.: Airborne intercomparison of vacuum ultraviolet fluorescence and tunable diode laser absorption measurements of tropospheric carbon monoxide, J. Geophys. Res. Atmos., 105, 24251-24261, 2000a.

Holloway, T., Levy, H., and Kasibhatla, P.: Global distribution of carbon monoxide, J. Geophys. Res. Atmos., 105, 12123-12147, 2000b.

Kaiser, A., Schelfinger, H., Spangl, W., Weiss, A., Gilge, S., Fricke, W., Ries, L., Cemas, D., and Jesenovec, B.: Transport of nitrogen oxides, carbon monoxide and ozone to the Alpine Global Atmosphere Watch stations Jungfraujoch (Switzerland), Zugspitze and Hohenpeissenberg (Germany), Sonnblick (Austria) and Mt. Krvavec (Slovenia), Atmos. Environ., 41, 9273-9287, 2007.

Khalil, M. A. K. and Rasmussen, R. A.: Carbon-Monoxide in the Earths Atmosphere - Indications of a Global Increase, Nature, 332, 242-245, 1988.

Khalil, M. A. K. and Rasmussen, R. A.: Global Decrease in Atmospheric Carbon-Monoxide Concentration, Nature, 370, 639-641, 1994.

Levy, H., Kasibhatla, P. S., Moxim, W. J., Klonecki, A. A., Hirsch, A. I., Oltmans, S. J., and Chameides, W. L.: The global impact of human activity on tropospheric ozone, Geophys. Res. Lett., 24, 791-794, 1997.

Logan, J. A., Prather, M. J., Wofsy, S. C., and McElroy, M. B.: Tropospheric Chemistry - a Global Perspective, Journal of Geophysical Research-Oceans and Atmospheres, 86, 7210-7254, 1981.

Luterbacher, J., Dietrich, D., Xoplaki, E., Grosjean, M., and Wanner, H.: European seasonal and annual temperature variability, trends, and extremes since 1500, Science, 303, 1499-1503, 2004.

Meszaros, T., Haszpra, L., and Gelencser, A.: Tracking changes in carbon monoxide budget over Europe between 1995 and 2000, Atmos. Environ., 39, 7297-7306, 2005.

Novelli, P. C., Masarie, K. A., Tans, P. P., and Lang, P. M.: Recent Changes in Atmospheric Carbon-Monoxide, Science, 263, 1587-1590, 1994.

Novelli, P. C., Masarie, K. A., and Lang, P. M.: Distributions and recent changes of carbon monoxide in the lower troposphere, $\mathrm{J}$. Geophys. Res. Atmos., 103, 19015-19033, 1998.

Novelli, P. C.: CO in the atmosphere: measurement techniques and related issues, Chemosphere - Global Change Science, 1, 115126, 1999.

Novelli, P. C., Masarie, K. A., Lang, P. M., Hall, B. D., Myers, R. C., and Elkins, J. W.: Re-analysis of tropospheric CO trends: Effects of the 1997-1998 wild fires, J. Geophys. Res.-Atmos., 108, 4464, doi:4410.1029/2002JD003031, 2003.

Pfister, G., Petron, G., Emmons, L. K., Gille, J. C., Edwards, D. P., Lamarque, J. F., Attie, J. L., Granier, C., and Novelli, P. C.: Evaluation of $\mathrm{CO}$ simulations and the analysis of the CO budget for Europe, J. Geophys. Res. Atmos., 109, doi:10.1029/2004JD004691, 2004.

Reimann, S., Manning, A. J., Simmonds, P. G., Cunnold, D. M., Wang, R. H. J., Li, J., McCulloch, A., Prinn, R. G., Huang, J., Weiss, R. F., Fraser, J., O’Doherty, S., Greally, B. R., Stemmler, K., Hill, M., and Folini, D.: Low European methyl chloroform emissions inferred from long-term atmospheric measurements, Nature, 433, 506-508, 2005.

Tanimoto, H., Sawa, Y., Matsueda, H., Yonemura, S., Wada, A., Mukai, H., Wang, T., Poon, S., Wong, A., Lee, G., Jung, J. Y., Kim, K. R., Lee, M., Lin, N. H., Wang, J. L., Ou-Yang, C. F., and Wu, C. F.: Evaluation of standards and methods for continuous measurements of carbon monoxide at ground-based sites in Asia, Papers in Meteorology and Geophysics, 58, 85-93, 2007.

Tanimoto, H., Sawa, Y., Yonemura, S., Yumimoto, K., Matsueda, H., Uno, I., Hayasaka, T., Mukai, H., Tohjima, Y., Tsuboi, K., and Zhang, L.: Diagnosing recent $\mathrm{CO}$ emissions and ozone 
evolution in East Asia using coordinated surface observations, adjoint inverse modeling, and MOPITT satellite data, Atmos. Chem. Phys., 8, 3867-3880, 2008, http://www.atmos-chem-phys.net/8/3867/2008/.

Thoning, K. W., Tans, P. P., and Komhyr, W. D.: Atmospheric Carbon-Dioxide at Mauna Loa Observatory. 2. Analysis of the NOAA GMCC Data, 1974-1985, J. Geophys. Res. Atmos., 94, 8549-8565, 1989.

Tressol, M., Ordonez, C., Zbinden, R., Brioude, J., Thouret, V., Mari, C., Nedelec, P., Cammas, J. P., Smit, H., Patz, H. W., and Volz-Thomas, A.: Air pollution during the 2003 European heat wave as seen by MOZAIC airliners, Atmos. Chem. Phys., 8, 2133-2150, 2008, http://www.atmos-chem-phys.net/8/2133/2008/.

Tsutsumi, Y. and Matsueda, H.: Relationship of ozone and CO at the summit of Mt. Fuji (35.35 degrees N, 138.73 degrees E, $3776 \mathrm{~m}$ above sea level) in summer 1997, Atmos. Environ., 34, 553-561, 2000.

Vestreng, V., Breivik, K., Adams, M., Wagener, A., Goodwin, J., Rozovskkaya, O., and Pacyna, J. M.: Inventory Review 2005, Emission Data reported to LRTAP Convention and NEC Directive, Initial review of HMs and POPs. Technical report MSC-W 1/2005, ISSN 0804-2446Technical report MSC-W 1/2005, ISSN 0804-2446, 2005.

Vollmer, M. K., Juergens, N., Steinbacher, M., Reimann, S., Weilenmann, M., and Buchmann, B.: Road vehicle emissions of molecular hydrogen (H2) from a tunnel study, Atmos. Environ., 41, 8355-8369, doi:10.1016/j.atmosenv.2007.06.037, 2007.

Whalley, L. K., Lewis, A. C., McQuaid, J. B., Purvis, R. M., Lee, J. D., Stemmler, K., Zellweger, C., and Ridgeon, P.: Two highspeed, portable GC systems designed for the measurement of non-methane hydrocarbons and PAN: Results from the Jungfraujoch High Altitude Observatory, J. Environ. Monit., 6, 234-241, 2004.

Wild, O. and Prather, M. J.: Excitation of the primary tropospheric chemical mode in a global three-dimensional model, J. Geophys. Res. Atmos., 105, 24647-24660, 2000.

Wotawa, G., Novelli, P. C., Trainer, M., and Granier, C.: Interannual variability of summertime $\mathrm{CO}$ concentrations in the Northern Hemisphere explained by boreal forest fires in North America and Russia, Geophys. Res. Lett., 28, 4575-4578, 2001.

York, D.: Least-Squares Fitting of a Straight Line, Can. J. Physics, 44, 1079-1086, 1966.
Yurganov, L. N., Blumenstock, T., Grechko, E. I., Hase, F., Hyer, E. J., Kasischke, E. S., Koike, M., Kondo, Y., Kramer, I., Leung, F. Y., Mahieu, E., Mellqvist, J., Notholt, J., Novelli, P. C., Rinsland, C. P., Scheel, H. E., Schulz, A., Strandberg, A., Sussmann, R., Tanimoto, H., Velazco, V., Zander, R., and Zhao, Y.: A quantitative assessment of the 1998 carbon monoxide emission anomaly in the Northern Hemisphere based on total column and surface concentration measurements, J. Geophys. Res. Atmos., 109, doi:10.1029/2004JD004559, 2004.

Yurganov, L. N., Duchatelet, P., Dzhola, A. V., Edwards, D. P., Hase, F., Kramer, I., Mahieu, E., Mellqvist, J., Notholt, J., Novelli, P. C., Rockmann, A., Scheel, H. E., Schneider, M., Schulz, A., Strandberg, A., Sussmann, R., Tanimoto, H., Velazco, V., Drummond, J. R., and Gille, J. C.: Increased Northern Hemispheric carbon monoxide burden in the troposphere in 2002 and 2003 detected from the ground and from space, Atmos. Chem. Phys., 5, 563-573, 2005, http://www.atmos-chem-phys.net/5/563/2005/.

Zander, R., Demoulin, P., Ehhalt, D. H., Schmidt, U., and Rinsland, C. P.: Secular Increase of the Total Vertical Column Abundance of Carbon-Monoxide above Central-Europe since 1950, J. Geophys. Res. Atmos., 94, 11021-11028, 1989.

Zander, R., Mahieu, E., Demoulin, P., Duchatelet, P., Roland, G., Servais, C., Maziere, M. D., Reimann, S., and Rinsland, C. P.: Our changing atmosphere: Evidence based on long-term infrared solar observations at the Jungfraujoch since 1950, Sci. Total Environ., 391, 184-195, 2008.

Zellweger, C., Ammann, M., Buchmann, B., Hofer, P., Lugauer, M., Ruttimann, R., Streit, N., Weingartner, E., and Baltensperger, U.: Summertime NOy speciation at the Jungfraujoch, $3580 \mathrm{~m}$ above sea level, Switzerland, J. Geophys. Res. Atmos., 105, 66556667, 2000.

Zellweger, C., Forrer, J., Hofer, P., Nyeki, S., Schwarzenbach, B., Weingartner, E., Ammann, M., and Baltensperger, U.: Partitioning of reactive nitrogen (NOy) and dependence on meteorological conditions in the lower free troposphere, Atmos. Chem. Phys., 3, 779-796, 2003, http://www.atmos-chem-phys.net/3/779/2003/. 